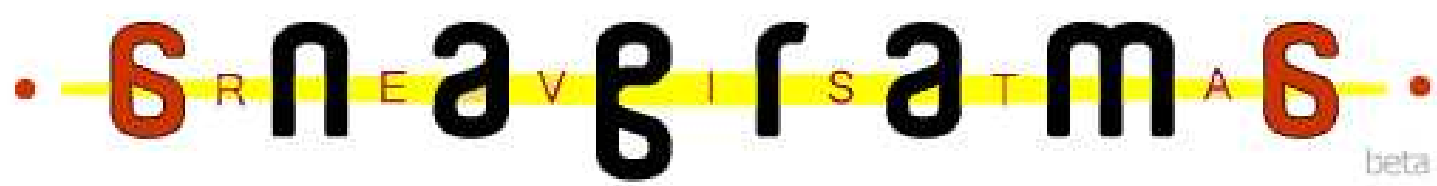

\section{Do Liuro às Telas: o fantástico em Harry Potter}

\section{Mariana Silueira dos Santos Rosa ${ }^{7}$}

Michel Goulart da Silua?

\section{Resumo}

Este trabalho tem como objetivo analisar comparativamente o primeiro livro da saga do jovem bruxo Harry Potter e sua versão cinematográfica. Para tanto, em um primeiro momento, faz-se a discussão acerca da narrativa fantástica e sua trajetória ao longo da história humana, identificando principalmente as características dos contos de fadas e os símbolos mobilizados nessas narrativas. Depois, analisa-se o primeiro livro da série a respeito de Harry Potter, identificando os elementos de contos de fadas nele presentes. Por fim, faz-se uma análise comparativa entre a forma da narrativa no livro e sua adaptação cinematográfica, identificando os pontos em comum e as diferenças, problematizando esses elementos também a partir dos elementos das narrativas fantásticas.

Palauras-chaue: Literatura fantástica; Contos de fadas; Adaptação.

Não é novidade a existência de narrativas fantásticas que conquistam grandes e diversos públicos, além de inúmeros admiradores. Ou seja, é comum acontecer, no cinema ou na literatura, de histórias como $O$ Senhor dos Anéis ou $O$ exorcista venderem muitos livros ou estourarem bilheterias. Não há necessariamente uma regra que torne possível prever se a história em livro ou em filme tem muito ou pouco potencial de venda, embora haja evidências de que um filme tenha maior apelo de massas em relação aos livros, pois possibilita que, ao mesmo tempo, um número maior de pessoas tenha acesso a uma única história. Entretanto, essa facilidade de alcançar o público não garante que um filme tenha maior sucesso que o livro.

Por outro lado, considerando a atração da humanidade por fábulas e a interação entre literatura e cinema por meio das adaptações, pode-se compreender que filmes com

\footnotetext{
${ }^{1}$ Graduanda de Pedagogia, habilitação em Educação, na Universidade Federal de Santa Catarina (UFSC).

${ }^{2}$ Graduando de História na Universidade do Estado de Santa Catarina (UDESC).
} 
elementos fantásticos, como é o caso das histórias de Harry Potter, cuja saga é contada ao longo dos sete anos em que o herói permanece na Escola de Magia e Bruxaria de Hogwarts, acabem provocando um grande impacto nas telas de cinema e, com certeza, em suas bilheterias. Essa narrativa, como se pretende mostrar neste trabalho, utiliza-se de muitos dos elementos fantásticos dos contos de fadas produzidos pela humanidade.

\section{Considerações sobre o fantástico}

Os elementos fantásticos não precisam ser considerados complexos ou ser encarados como algo fora do normal, pois não se limitam a isto. O fantástico pode ser definido como "o irreal no sentido estético daquilo que é apenas imaginável”, aquilo "que não é visível aos olhos de todos, que não existe para todos, mas que é criado pela imaginação, pela fantasia de um espírito" (HELD, 1980, p. 25). O fantástico não está separado ou afastado da realidade concreta, pois ele faz parte desta realidade, sendo, portanto, expressão e produto da imaginação do homem. Segundo Jacqueline Held (1980, p. 28), pode-se encontrar sua fonte nas experiências cotidianas, com personagens conhecidas e em acontecimentos vividos.

Essa atração exercida pelo fantástico sobre o homem pode ter iniciado com as primeiras interpretações dadas aos fenômenos da natureza, como as chuvas e os relâmpagos, e para tragédias naturais, como terremotos e erupções de vulcões, que poderiam, por exemplo, devastar colheitas ou levar à morte centenas de pessoas. Explicações fantásticas foram atribuídas aos fenômenos que o homem não poderia compreender e explicar, sendo produto disso, entre outras coisas, os vários mitos e deuses da antiguidade, ou até mesmo as religiões criadas mais recentemente. Um dos resultados da relação entre o homem e as diferentes manifestações do fantástico é a criação de narrativas, orais ou escritas, que são produtos da própria experiência humana, pois estão relacionadas à vida ou à produção material do homem (OHLWEILER, 1988).

No decorrer da história humana, essas narrativas, muitas delas apenas novas versões das narrativas contadas pelos primeiros grupos humanos, vêm exercendo forte sedução sobre os mais diferentes tipos de pessoas, sendo possível explicar esse fenômeno, segundo Nelly Coelho (1987, p. 10), pelo fato de o homem, desde o início de sua existência, "ter sentido a presença (ou a força) de poderes muito maiores do que sua própria vontade e poder pessoal ou de mistérios que o atingissem, sem que sua mente conseguisse explicar, conhecer ou compreender". 


\section{Os contos de fadas}

Não apenas as interpretações fantásticas de fenômenos da natureza permanecem entre os homens, influenciando suas vidas, como as narrativas de caráter fantástico continuam a exercer forte sedução sobre eles. Toda a trajetória percorrida pela humanidade, nas diferentes regiões do globo, deu origem, em cada lugar, a uma ampla quantidade e variedade de narrativas (heróicas, dramáticas, eróticas entre outras) sob influência do fantástico, levando ao surgimento de um

imenso caudal narrativo (hoje transformado ou simplificado em literatura folclórica ou literatura infantil), [onde] duas formas destacam-se não só pela divulgação que alcançaram através dos séculos, mas principalmente pela identificação feita entre uma e outra (COELHO, 1987, p. 11).

Essas duas formas mencionadas por Nelly Coelho são os contos de fadas e os contos maravilhosos, sendo possível definir o primeiro, que nos interessa nesta discussão, da seguinte forma:

Com ou sem a presença de fadas (mas sempre com o maravilhoso), seus argumentos desenvolvem-se dentro da magia feérica (reis, rainhas, príncipes, princesas, fadas, gênios, bruxas, gigantes, anões, objetos mágicos, metamorfoses, tempo e espaço fora da realidade conhecida etc.) e têm como eixo gerador uma problemática existencial. Ou melhor, têm como núcleo problemático a realização essencial do herói ou da heroína, realização que, via de regra, está visceralmente ligada à união homem-mulher (COELHO, 1987, p. 13, grifos da autora).

Antes de qualquer coisa, um conto de fadas pressupõe a existência de um mundo paralelo, ou ao menos a ocorrência de forças que não fariam parte de forma coesa do que poderia ser chamado de mundo "normal", ou de mundo real. Existindo esse outro mundo, ou essas outras forças, o fantástico passa a ser algo verossímil, ou seja, torna-se passível de ser entendido e aceitável. Os contos de fadas, bem como as demais narrativas fantásticas, acabam por reunir, materializar e traduzir "todo um mundo de desejos: compartilhar da vida animal, libertar-se da gravidade, tornar-se invisível, mudar seu tamanho e resumindo tudo isso - transformar à sua vontade o universo" (HELD, 1980, p. 25).

O conto de fadas também está relacionado à realização existencial do herói, isto é, à superação de numerosos obstáculos em busca de um determinado objetivo, como o crescimento pessoal, um tesouro, um amor, entre outros. Disso pode-se depreender que há no conto de fadas a presença de um aspecto moral, representado pela busca de um ideal; ideal este que pode assumir diferentes formas, dependendo da sociedade e da época em que se desenvolve a história. Pode ser um grande amor, ou um crescimento moral, ou outro 
aspecto apropriado como positivo pela sociedade na qual o conto foi produzido. Conforme Coelho (1987, p. 13, grifos da autora),

a elaboração básica do conto de fadas expressa os obstáculos ou provas que precisam ser vencidas, como um verdadeiro ritual iniciático, para que o herói alcance sua auto-realização existencial, seja pelo encontro de seu verdadeiro eu, seja pelo encontro da princesa, que encarna o ideal a ser alcançado.

Os contos de fadas, em sua grande maioria, seguem uma estrutura de narração semelhante entre si, começando "por um dano ou um prejuízo causado a alguém (rapto, exílio), ou então pelo desejo de possuir algo (o czar manda seu filho buscar o pássaro de fogo)", tendo como desenvolvimento a "partida do herói, encontro com o doador que lhe dá um recurso mágico ou um auxiliar mágico munido do qual poderá encontrar o objeto procurado". Segue-se "o duelo com o adversário (cuja forma mais importante é o combate com o dragão), o retorno e a perseguição" (PROPP, 1997, p. 4).

Portanto, torna-se possível perceber nos contos de fadas uma estrutura básica, com uma narrativa que tem início em problemas surgidos no mundo real, partindo para a busca por soluções no mundo da fantasia, e com um desfecho que se dá no retorno ao mundo real (AGUIAR apud ABRAMOVICH, 2002, p. 120). Ou seja, o herói sai de seu mundo, recebe de alguém mais experiente algo que lhe será útil no em sua jornada, encontrando aliados e inimigos, até o momento em que ocorre o desafio final, e o herói retorna ao seu reino. Encontra-se nesse ponto

\begin{abstract}
a mensagem que os contos de fadas transmitem à criança de forma variada: que uma luta contra dificuldades graves na vida é inevitável é parte intrínseca da existência humana mas que, se a pessoa não se intimida e se defronta resolutamente com as provações inesperadas e muitas vezes injustas, dominará todos e ao fim emergirá vitoriosa (BETTELHEIM, 2008, p. 15).
\end{abstract}

Essas conclusões a respeito da presença de uma provável universalidade nas narrativas fantásticas foram tema de investigação de alguns autores, contemporaneamente balizando em grande medida a indústria do cinema estadunidense. Há antecedentes dessas reflexões na produção de Vladimir Propp, principalmente em um estudo publicado no ano de 1946, que toma como objetos de análise alguns contos tradicionais russos. Três anos após a publicação desse trabalho, Joseph Campbell chegou a conclusões semelhantes às de Propp, tendo como objeto de análise o que poderia ser denominado de "mitos ocidentais". Partindo das idéias dos arquétipos desenvolvidas pelo psicanalista C. G. Jung, Campbell deu origem ao que ficou conhecido como a "jornada do herói”. No início da década de 1990, Cristopher Vogler traduziu as idéias de Campbell para o cinema, transformando sua 
obra A jornada do escritor em um livro exaustivamente lido em Hollywood, e dando uma consistente base teórica para a elaboração dos roteiros ali produzidos (MACIEL, 2003, p. 62-7).

\section{O mundo de Harry Potter}

$\mathrm{Na}$ trajetória vivida por Harry Potter aparecem muitos elementos característicos dos contos de fadas. Na primeira parte da história, Harry Potter e a pedra filosofal, o protagonista parte para seu primeiro ano na Escola de Magia e Bruxaria Hogwarts, onde conhece Ronald Weasley e Hermione Granger, que se tornariam os seus melhores amigos. Certo dia, após se perder em meio às mais de cento e quarenta escadas da escola, o trio chega ao terceiro andar do imenso prédio, um espaço proibido para os alunos. Lá eles encontram Fofo, um cão gigante de três cabeças, que mais tarde descobrem estar guardando a Pedra Filosofal, um poderoso objeto que continha um elixir da vida capaz de tornar imortal quem o tomasse. Depois de alguns acontecimentos estranhos, as crianças passam a suspeitar que Severus Snape, o professor de Poções, estaria tentando roubar a pedra filosofal. Mais tarde eles vêm a descobrir que quem realmente queria roubar a pedra era o professor de Defesa Contra as Artes das Trevas, Cessar Quirrell, que carregava em sua cabeça, escondido debaixo de um turbante, a única coisa que sobrou de Voldemort. Voldemort fracassa novamente ao tentar destruir Harry, e acaba provocando a morte de Quirrell.

Um primeiro elemento dos contos de fadas presente nessa história vivida por Harry Potter tem a ver com a tragédia sofrida pelo herói, que ainda bebê perde os pais e quase é morto. Um segundo elemento presente é a questão da existência de um mundo fantástico, paralelo o mundo dos "trouxas" (todos aqueles que não são bruxos), onde todos os feitos fantásticos são verossímeis e até mesmo corriqueiros. Em terceiro, há a trajetória traçada para o herói, uma clara reprodução dos muitos contos fantásticos surgidos ao longo da humanidade. Podem ainda ser destacados outros elementos, como o espelho, enquanto uma espécie de portal e revelador de íntimos desejos; o jogo de xadrez que adquirira vida; a presença do vilão, que é construída aos poucos na narrativa, iniciada pelo mero mito sobre o qual todos falam até assumir uma forma corpórea contra a qual o herói precisa lutar.

Contudo, talvez o elemento mais importante para relacionar esta primeira parte da história de Harry Potter aos contos de fadas seja a estrutura da narrativa, muito próxima às descrições feitas por Coelho (1987) e Propp (1997). Trata-se de uma narrativa que 
apresenta de forma explícita uma disputa entre o que se convencionou chamar, ao longo da história da humanidade, de Bem e Mal. Essa narrativa procura mostrar os primeiros passos que o herói, numa espécie de ritual de iniciação, tem de dar, no sentido de fazer uma opção entre os dois caminhos. Segundo Bruno Bettelheim (2008, p. 16),

em praticamente todo conto de fadas, o bem e o mal são corporificados sob a forma de algumas personagens e de suas ações, uma vez que o bem e o mal são onipresentes na vida e as propensões para ambos estão presentes em todo homem. É essa dualidade que coloca o problema moral e requer a luta para resolvê-lo.

O fato de ter sido o único sobrevivente a um ataque do Lord Voldemort, o maior bruxo do Mal de que já haviam tido notícias, fez com que fosse criado um mito em torno da figura de Harry Potter, projetando para ele um futuro repleto de atos grandiosos. "Ele vai ser famoso, uma lenda. Eu não me surpreenderia se o dia de hoje ficasse conhecido no futuro como o dia de Harry Potter. Vão escrever livros sobre Harry. Todas as crianças no nosso mundo vão conhecer o nome dele" (ROWLING, 2000, p. 17), afirma a professora Minerva McGonagall.

Nesse mito criado em torno de Harry Potter, é dado como certo que no futuro Harry virá a se tornar um grande bruxo, no entanto isso não significa uma certeza de que ele será um grande bruxo do Bem. A ausência desta certeza se deve ao exemplo de Voldemort, um grande bruxo que seguiu pelo caminho do Mal, conquistando, pelo medo ou pelas promessas de poder e ganhos futuros, inúmeros seguidores. Nessa primeira parte do conjunto dos sete livros, que representam os sete anos de Harry na escola de magia e bruxaria, busca-se apresentar alguns elementos que ajudam a indicar o caminho que viria a ser escolhido pelo herói. Esse caminho é construído de forma extremamente lenta e gradual, sendo permeado por medos e tentações das mais variadas, mas prossegue em direção à vitória e ao fortalecimento do Bem.

Essa caminhada apresenta alguns elementos que ajudam a traçar o caminho do jovem bruxo. Um primeiro a ser destacado é o momento em que Harry compra sua varinha e, sem saber, é escolhido por uma varinha "irmã" da de Voldemort, ou seja, uma varinha destinada a bruxos de feitos grandiosos. Um segundo elemento tem a ver com a escolha da casa: no momento da seleção, Harry deseja não ir para Sonserina, de onde tinham surgido todos os bruxos que haviam seguido pelo caminho do Mal; ou seja, Potter acreditava que não ir para esta casa significaria que ele não iria para esse caminho. Um terceiro elemento se refere à escolha dos amigos, isto é, à negação que Harry faz da família de bruxos "melhores", mais "puros" ou mais "poderosos", como os Malfoy (inclusive, ao longo de 
algumas das aventures de Harry será explorado o vínculo do patriarca da família Malfoy com Voldemort).

Outra idéia mostrada de forma clara é a de que um bom coração conquista sempre aliados bons e fiéis. Um deles é Hagrid, cicerone, ajudante e protetor do grupo de heróis, que não teme inclusive a utilização de métodos que quebrem as regras da escola para ajudar na luta contra o Mal. Também estão entre essas pessoas o bruxo Alvo Dumbledore, poderoso diretor de Hogwarts, e mesmo a sisuda professora Minerva, que toleram as indisciplinas e desobediências de Harry e seus amigos. Mas, até o final da saga, os principais aliados de Harry Potter são Hermione, filha de trouxas, que em sua esperteza e dedicação à leitura tem sempre uma solução lógica para os problemas que surgem, e Rony, oriundo de uma família de bruxos de poucas posses, cuja lealdade e coragem sempre estão à disposição dos dois parceiros, Hermione e Harry. Isso, somado à disposição, iniciativa, coragem e ao bom coração de Harry, constroem aspectos essenciais para o fortalecimento do Bem.

O primeiro grande desafio para Harry Potter chega ao final da primeira parte de sua história. Frente a frente com Voldemort, o poderoso Lorde das Trevas oferece a Harry uma suposta aliança, capaz de torná-lo muito poderoso. Contudo, o bom coração do jovem bruxo não se rende, fazendo com que a pedra filosofal, cuja posse só teria quem a desejasse sem visar uso próprio, simplesmente apareça em seu bolso e lhe dê poderes para derrotar Voldemort. Ou seja, ao final temos resolvido o grande mistério: o caminho pelo qual seguiria o jovem Potter é o do Bem, o mesmo seguido por seus pais, ou seja, o caminho trilhado pelo mestre Dumbledore e por outros tantos bruxos, contra Voldemort, o grande representante do Mal. Portanto, para o jovem Harry Potter começa a ser mostrado o caminho que o levaria a se tornar um grande bruxo, optando pelas forças do Bem e tendo como principal tarefa de sua saga derrotar seu mais antigo e poderoso inimigo, Voldemort.

Temos, ao final, tanto a definição acerca da índole do herói como a demonstração de uma moral: a escolha entre seguir pelo caminho do Bem ou pelo caminho do Mal é feita pela própria pessoa, superando os percalços impostos pela vida e seus próprios limites. As tentações e hesitações pelas quais Harry passou são várias, incertas, mas um bom coração acabará sempre, ainda que em dificuldades, seguindo o rumo do Bem. Bruno Bettelheim (2008, p. 34) lembra que 
os contos de fadas dão a entender que uma vida compensadora e boa está ao alcance da pessoa apesar da adversidade - mas apenas se ela não se intimidar com as lutas arriscadas sem as quais nunca se adquire a verdadeira identidade.

O herói Harry é o grande exemplo. E sabe-se, ao final da narrativa, que ele fará feitos grandiosos, e que esses feitos grandiosos serão para o Bem, pois seu coração é puro.

\section{Do liuro às telas}

Neste trabalho analisamos, até aqui, a narrativa de Harry Potter de forma geral, sem demarcar diferenças entre o livro e o filme, na medida em que as semelhanças entre ambos são bastante substanciais. No que se refere à adaptação do livro para o filme, esta primeira parte se mostra como uma espécie de transcrição, procurando manter certa fidelidade ao texto original, sendo, de certa forma, um resumo da obra literária. São tomados os elementos fundamentais da história em livro, mas esses são contados de forma mais sucinta, perdendo-se, assim, detalhes das personagens e do mundo criado, ou mesmo elementos que diferenciam os dois mundos apresentados, o mundo dos bruxos e o mundo dos trouxas.

É imprescindível que a adaptação cinematográfica mantenha uma narrativa movimentada, fazendo a construção das personagens na medida em que a história é contada, sem detalhes supérfluos em excesso, que possam dar um tom prolixo e fazer com que a narrativa se torne enfadonha. No caso das obras literárias que narram a saga de Harry Potter, um aspecto que facilita o trabalho de adaptação é o fato de o próprio livro, embora não seja um roteiro de filme, ser construído de uma forma na qual as cenas parecem ter sido pensadas em seus detalhes imagéticos e conforme uma narrativa por cenas.

Comparando o livro e o filme, podemos encontrar alguns exemplos de diferenças que não modificam de forma substancial a narrativa na adaptação. Por exemplo, logo no início da narrativa na obra literária, quando decidem ir ao zoológico, a família de Harry discute muitas saídas para o que fazer com o jovem bruxo, tendo em vista que seus tios não gostariam de levá-lo ao passeio e que a pessoa que normalmente cuidava do menino não poderia fazê-lo naquele dia. No filme essa passagem, que no livro é bastante longa e onde são levantadas muitas possibilidades para a resolução do problema, é resumida em um breve diálogo entre Harry e o tio quando todos vão ao zoológico, em que o segundo alerta Harry para que ele não "apronte" nada.

Em outra passagem, quando Hagrid vai buscar Harry no mundo dos trouxas, o diálogo entre ambos no filme é bastante mais curto. O filme explica brevemente que Harry 
é um bruxo e vai para uma escola, onde irá se formar como tal. Por outro lado, no livro Harry não apenas hesita diante daquela figura desconhecida, como consegue acreditar na informação de que ele próprio seja um bruxo, apesar de todas as coisas estranhas que lhe acontecem no decorrer de sua vida. Nesta mesma noite ele também conhece em detalhes o que havia acontecido na noite em que ele sobreviveu e seus pais foram assassinados por Voldemort.

\section{Considerações finais}

Percebe-se, por essa análise, que na primeira parte da trajetória vivida por Harry Potter são tomadas as experiências das narrativas fantásticas produzidas pela humanidade em sua história. Além de serem tomados inúmeros elementos feéricos, a própria construção da narrativa coloca como modelo as histórias mais antigas, principalmente de contos de fadas. Harry Potter é herdeiro dessa forma de abstração conhecida como fantástico que, embora relacionada com a realidade, dela se desprende.

Por outro lado, a divisão mecânica entre o Bem e o Mal, que estar relacionada à época em que o homem encarava a natureza como um lugar desconhecido e temia o que considerava como seus perigos, vendo neles algo de mal, está fortemente presente nas obras a respeito de Harry Potter. Nessas obras tenta-se mostrar a força do Bem, ou seja, é previsível que o Mal será derrotado ao final de toda a trajetória de Harry.

Certamente não há que se criticar a vitória do Bem sobre o Mal, mas essa questão está muito mais no campo da Moral do que dos estudos sobre criação literária e cinematográfica. Portanto, essa possível relação entre duas forças que se apresentam como antagônicas talvez seja mais emaranhada e complexa do que afirmam os textos sobre o fantástico até hoje produzidos.

\section{Referências Bibliográficas}




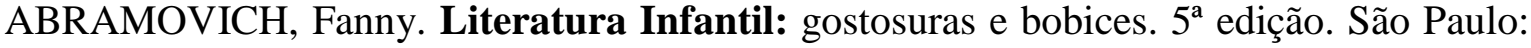
Scipione, 2002.

BETTELHEIM, Bruno. A psicanálise dos contos de fadas. $22^{a}$ ed. São Paulo: Paz e Terra, 2008.

COELHO, Nelly Novaes. O conto de fadas. São Paulo: Ática, 1987.

HELD, Jacqueline. O imaginário no poder: as crianças e a literatura fantástica. São Paulo: Summus, 1980.

MACIEL, Luis Carlos. O poder do clímax: fundamentos do roteiro de cinema e TV. Rio de Janeiro: Record, 2003.

OHLWEILER, Otto Alcides. Origem e evolução da ideologia: do pensamento mágico ao pensamento científico. Porto Alegre: Ed. da UFRGS, 1988.

PROPP, Vladimir. As raízes históricas do conto maravilhoso. São Paulo: Martins Fontes, 1997.

ROWLING, Joanne Kathleen. Harry Potter e a pedra filosofal. Rio de Janeiro: Rocco, 2000 . 